\title{
The right to die with dignity in Colombia
}

\begin{abstract}
The right to die with dignity in Colombia is translated in the decriminalization that was done of the euthanasia by means of the judgment C-2391 of 1997, nevertheless, until the year 2014 the elements were established to effect the euthanasia in the system of Health, which allowed that a Colombian located in Pereira's municipality in the Hospital Oncologists of West to his 79 years of age, with suffering cancer was dying with dignity on July, three (3), 2015. There has been only 28 cases presented to which the euthanasia has been proceeded, but there hasn't been a simple situation because there exist normative emptiness's that through the Constitutional Court have been filling, corporation that it exhorted, to the corresponding entities, in order that they regulate the topic of the euthanasia in order to proceed with every request and to allow that the citizens with terminal illnesses, both adults and minors, could finish his life dignity.
\end{abstract}

Keywords: death, human dignity, euthanasia, decriminalization, terminal illness
Volume 6 Issue 6 - 2018

Lynda Lynda López Benavides
University Autónoma de Colombia, Colombia

Correspondence: Lynda Layda López Benavides, Lawyer of the University Autónoma de Colombia, specialist in commercial law of the University libre de Colombia, studying magister in law at the University Sergio Arboleda de Colombia, Colombia, Emaillylavda@gmail.com

Received: April 25, 2018| Published: November 27, 2018

\section{Introduction}

The euthanasia is a controversial topic when we talk about moral ethics, political and judicial character, which it has inspired States as the Colombian to legalizing the practice of taking the life from a subject when he suffers a terminal illness. In Colombia it is legalized from 1997, but at present it does not have a norm that regulates it, the Congress of the Republic has not declared itself opposite to the topic for the strong influence of the Catholic Church in laws that can question religious principles. This medical practice allows that the terminal patients who do not want to continue suffering for pathology without treatment and tortuous days can die with dignity. With this postulate euthanasia was decriminalized and until 2014 the issue was again taken up, laying down rules that should precede it, which reflects that it could not be materialized as it was sought at the time, the Constitutional Court had to intervene through action of guardianship ${ }^{2}$ to urge the Ministry of Health to proceed to direct the health providers about euthanasia. Therefore, the present study will show the countries that have regulated euthanasia and other similar practices for the same purpose, at the same time will set the elements that are required to practice it not only in Colombia but in the countries that currently apply it, Likewise, the judicial progress that Colombia has had in this regard will be reviewed, which was extended to minors. The previous thing was achieved with the meticulous reading of the sentences that will be cited in the course of the presented work, of the doctrine referring to the subject, of the news review, news releases, and videos among other things.

The aforementioned with the intention of contributing to the investigation in an objective, historical, clear and precise way avoiding the confrontations that the doctors present in their office and the request for euthanasia, the lack of personnel for the procedure, the few facilities and little respect to the judicial terms that are established to fulfill the purpose of giving the patient a death with dignity.

\section{Definition and classes of euthanasia}

Euthanasia in its Greek definition means "good death" of the word eu that means "good", and thanatos that refers to "death". On the other hand, for the real academy it means deliberate intervention to put an end to the life of a patient without perspective of cure, also defines it as a death without physical suffering. On the other hand, euthanasia is indicated as a medical intervention that induces the death of a fellow, who voluntarily requested it to end their suffering. ${ }^{3}$ The Constitutional Court of Colombia in judgment T-970 of 2014, ${ }^{4}$ determined the elements that must concur at the time of the procedure, which are that:

I. The passive subject suffers from a terminal illness;

II. A doctor must be the active subject who performs the act or omission to end the patient's pain and;

III. It must be produced by specific request, reiterated and informed of the patients.

Once the above elements have been accredited, it can be done in two ways, through active euthanasia or passive euthanasia. The first one defined as "A practice that involves the direct intervention of the health professional, which leads to the death of a person who is a victim of a disease with no chance of cure, through medications that lead to such result, this is given to the patient's direct request ", the second is defined as" A death by omission, that is to say, the necessary care is not taken for the person to survive with the intention of hastening death ", in this kind of euthanasia the behavior of the doctor is "not to do" (Guerra Perilla, 2016, p. 26). We also find direct euthanasia defined as an intentional provocation by the doctor who seeks to end the patient's life. Instead, we find indirect euthanasia when there is no intention to cause the death of the patient. The difference between the previous classifications corresponds to that in one there is the will of the patient; while in the other one the doctor's will is seen. In this regard, similar procedures are found: assisted suicide, palliative care, cacotanasia, and dysthanasia.

\section{Countries that accept euthanasia}

The legalization or decriminalization of euthanasia in different parts of the world depends on the ethical, cultural, religious or juridical conception that is held, considering that it is a complicated issue within the States that to date has been difficultly legislated. The first country that approved active euthanasia was the Parliament of the Netherlands on April 10, 2001, later; Belgium on May 16, 2002, also countries such as Luxembourg, and Colombia, this last country has been the only country in Latin America that allowed the euthanasia. In Uruguay and Argentina they regulate issues of dignified death but euthanasia is not allowed as in Colombia since $1997 .^{5}$ 
In Holland, the following requirements are presented for its legality:

I. That the patient is resident in the Netherlands.

II. That the doctor is sure that the elevated request comes from the patient voluntarily and consciously. It is valid if it was made in advance by the patient in a private document.

III. That the pathology that suffers does not have possibility of improvement and the suffering is confirmed as unbearable.

IV. That the patient be informed of their particular situation and future prospects.

V. That the request be consulted by two doctors.

VI. That the procedure is carried out with the utmost care and professionalism.

VII. On the other hand, in Belgium the following requirements are required:

VIII. That the patient is emancipated, capable and aware of the request. It is one of the few countries that allow euthanasia in minors, the special condition in the case is that the child has the ability to reason.

IX. That the petition be presented voluntarily without harassment and pressure of any kind.

X. That the patient presents an incurable disease, with constant psychic and physical suffering.

XI. The doctor must inform the applicant of their health status and life expectancy. Also, the alternatives of treatment, therapeutic possibilities, or palliative care.

XII. The petition must be submitted in writing, or have been made in advance.

XIII. It requires you to seek an evaluation from another health professional.

From the above, it can be shown that the requirements in one or the other country are not excluded, they have in common that there is a terminal illness, incurable, and constant suffering, at the same time that they have two medical concepts about the case, that the petition be voluntary, in full use of capabilities and verifiable Situation that also happens in Colombia with the guidelines made by the Constitutional Court in the T-970 Judgment of 2014 set forth in articles 15 and following of Resolution 1216 of 2015 issued by the Ministry of Health in the following manner:

I. It must be a patient in terminal phase, with oncological pathologies and not oncologies, that has the capacity to express itself verbally or in writing. Adults with psychiatric disorders are excluded from this case, even when they expressed their will in advance.

II. It must be a disease with intolerable suffering, which does not have options for improvement and there are no alternative treatments.

III. The request must be submitted by the patient voluntarily, repeatedly, free of any influence by their family and social environment, can be submitted in writing or verbally, or be attached to a document made in advance.

IV. It is checked whether or not you have mental disorders or decreased decision making by a psychiatrist or psychologist.

$\mathrm{V}$. The application is presented before an interdisciplinary scientific committee as the second evaluator of the application.

VI. The request can be abandoned at any time.

VII. If there is a discrepancy between the attending physician and the Committee, the concept of another professional will be sought and the case will be re-evaluated.
The Committee that is referred to is made up of a doctor with specialty in the pathology that the patient suffers, different from his treating doctor, a lawyer, and a psychiatrist or clinical psychologist. Which can not be objectors of the procedure that anticipates the death in a terminal patient to die with dignity? On the other hand, regarding the United States it is indicated that euthanasia is not legalized, it is practiced assisted suicide in the States of Washington, Oregon and Montana, that procedure also applied in Switzerland is defined "as the orientation made by the doctor, tending to provide people who with their consent want to end their life with doses or drugs that carry for this purpose (Guerra, Perilla, 2016, p. 26). It can be done in a direct way, which is when the doctor intervenes, and the other one we can call it indirect when by the doctor's instructions substances are applied that lead to his death.

\section{Precedent jurisprudential of the euthanasia in Colombia}

The Constitutional Court $^{7}$ that was created by the Political Constitution of 1991, is an organism entrusted with the guardianship of the integrity and supremacy of the Political Charter, whose functions were described in article 241, and is part of the judicial branch of the Public Power. The Court, as head of the constitutional jurisdiction has the task of reviewing, analyzing and interpreting the norms contained and established for the country in general. Condition that allowed in 1997 to review the constitutionality of the crime of mercy established in article 326 of Decree $100^{8}$ of 1980 that indicated "who kills another for mercy, to end intense suffering from bodily injury or serious and incurable disease, will incur prison from six months to three years."

In the considerations of the Court, the collision of the right to live and human dignity was resolved, postulating that it is only possible to protect the dignified and freely desired life of its owner "the State can not oppose the decision of an individual who does not wish to continue living and asking him to help him die, when he suffers from a terminal illness that produces unbearable pain incompatible with his idea of dignity." From that moment, Colombia became the first country in Latin America to approve the euthanasia of terminally ill patients. However, as said corporation does not have legislative faculties, it decided to urge the Congress of the Republic to legalize the subject of study. In addition to the foregoing, the Court recognized that the right to die with dignity has the status of fundamentals whenever:

I. The free and informed consent of the patient mediates;

II. Practiced by a doctor;

III. The taxpayer suffers from a terminal illness that causes suffering.

In these events, the behavior of the active subject is not unlawful and therefore there is no crime. In case of missing any element, the person will be criminally responsible for homicide. After sixteen years of that milestone sentence that allowed euthanasia in Colombia, a Colombian with cancer at the age of 79 filed a guardianship action ${ }^{9}$ because the health entity refused to perform euthanasia, since to date it has not been $\mathrm{He}$ found the procedure regulated, because the Congress of the Republic had not legislated on the matter. The T-970 tutelage of 2014 allowed the discussion about euthanasia to be reopened, and the Court ordered the Ministry of Health to issue a directive to all health service providers to form a group of interdisciplinary experts who will perform various functions when is in the presence of cases in which the right to die with dignity is requested. Likewise, the Court exhorts the Congress of the Republic to proceed to regulate the fundamental right to die with dignity. Apart from the foregoing, the Court indicated the elements that the euthanasia request must meet in order to be 
legal, and that no liability is discharged to the doctor or EPS in its place, which were referred to in the previous section of this article Investigation reason why they do not return to cite. The previous decision is of a constitutional nature that affected the Catholic Church, because the Colombian State is a secular state, its culture, ethics and politics is greatly influenced by the Catholic Church, which classifies euthanasia as a mortal sin. On the other hand, the person who benefited from the decision was called Ovidio González, 79 years old, who suffered from cancer and died on July 3, 2015 at the Hospital de Oncológicos de Occidente in Pereira. In his honor, the twenty-third of January was commemorated as the day of euthanasia in Colombia. ${ }^{10}$ After that decision, the Ministry of Health on April 20, 2015 issued Resolution 1216 by means of which the regulations were established to exercise the right to die with dignity, accentuating the protocols indicated by the Constitutional Court in the sentence T-970 of 2014, and fixed others of a technical nature such as:

I. Define terminal patient,

II. Determine the creation of the Interdisciplinary Scientific Committee,

III. The functions of the committee,

IV. The functions of the IPS,

V. Functions of the EPS,

VI. The procedure, and

VII. The objection to the doctors.

With the above, a jurisprudential line was introduced that allows euthanasia in Colombia, At present 28 procedures have been developed according to data by the Ministry of Health, however specific that there are more applications that have been denied because they do not meet the requirements to end it.

Next, Table 1 reflects the sentences that have studied the subject or have related it and have been perfecting euthanasia in Colombia. (Table 1)

\begin{tabular}{|c|c|}
\hline Judgement & Observation \\
\hline C-239/1997 & Decriminalize euthanasia. \\
\hline T-970/20I4 & Regulation the elements to allow euthanasia. \\
\hline C-233/20I4 & It deals with alternative treatments to euthanasia. \\
\hline C-327/2016 & They analyze the existence and purpose of people. \\
\hline $\mathrm{T}-423 / 2017$ & $\begin{array}{l}\text { Breach of the facilities of the Healthcare Provider to } \\
\text { apply euthanasia. }\end{array}$ \\
\hline $\mathrm{T}-322 / 2017$ & Prohibits euthanasia for cases of depression. \\
\hline T-544/2017 & It allows euthanasia in children and adolescents. \\
\hline $\mathrm{T}-72 \mathrm{I} / 2017$ & It empowers family members to authorize euthanasia. \\
\hline
\end{tabular}

The constitutional balance of euthanasia that flows from the decisions issued by the Constitutional Court ${ }^{11}$ has demonstrated as a fundamental premise the dying with dignity, the Court opts in the in dubio pro libertate, according to which, in case of conflict between freedom or legal equality, or another principle that opposes it prevails. In the case of study when the patient lacks real possibilities of healing he suffers intense suffering and requests that he be killed, not allowing him to achieve the effectiveness of his right to end an existence that he considers disgraceful, if it constitutes interference intense in the free development of personality and human dignity. ${ }^{3}$

\section{The euthanasia in minors in Colombia}

Judge Speaker Gloria Stella Ortiz Delgado ${ }^{12}$ on August twenty- fifth (25) of 2017 by means of sentence T-544 ${ }^{13}$ of 2017 , allowed euthanasia in minors, for which she gave the term of four months to the Ministry of Health for its respective regulations. Through Resolution 825 of 2018, the Ministry of Health regulated euthanasia in minors, once again one of the first countries in Latin America to make such provisions. However, there must be some elements to approve the death worthy of a child and adolescent. Well, young people over 14 do not need parental authorization, children between 12 and 14 years of age compulsorily require the consent of their parents, and boys and girls between 6 and 12 years old must demonstrate a "neurocognitive development and exceptional psychological that allows them to make a free, voluntary, informed and unequivocal decision in the medical field and their concept of death reaches the expected level for a child over 12 years old".

On the other hand, newborns, infants, and those with altered states of consciousness cannot request euthanasia.

With regard to the other elements, it can be said that they are similar to those contemplated for an adult, only that the Committee that will evaluate the request will be made up of a pediatrician, a psychiatrist and a lawyer, the difference between the Resolution 1216 of 2015 with Resolution 825 of 2018, is that, in the first the doctor who is in the Committee must have knowledge of the pathology that relates to the patient, on the other hand, in the second what matters and interests in the case of the Minor is determining your state of consciousness with your illness, life and dignified death that you seek with the request. Likewise,

I. No influence can be mediated by family members,

II. Requires the concept of two doctors,

III. The request must be written or verbal but conscious, voluntary and reiterative about dying with dignity intermediate of euthanasia.

Today the first case of euthanasia in minors has not been presented, unfortunately the two guardianships ${ }^{14}$ that were presented requesting approval for euthanasia, when the substance of the matter was decided, lacked purpose because the minors had already died for their The same disease, however, allowed the Colombian legal system to advance by developing one of the gaps that affected the citizenry on this issue.

\section{Conclusion}

In conclusion, the following:

I. In Colombia, euthanasia has been decriminalized since 1997. The elements and the process of this practice were allowed by the intervention of the Constitutional Court through sentences.

II. Resolutions 1216 of 2015 and 825 of 2018 regulate the technical and administrative procedure that must be required to carry out the euthanasia of an adult and of a child or adolescent.

III. The Ministry of Health accepted the guidelines established by guardianship 970 of 2014, since the Congress of the Republic for more than sixteen years has not been able to regulate euthanasia in Colombia.

IV. It is a fundamental right to die with dignity, according to the in dubio pro libertate, where autonomy prevails, and the patient's freedom when his own life has been devalued and as the owner of that right he wishes to renounce it.

V. Euthanasia in Colombia means ending the life of a person suffering from a terminal illness; with constant pain and suffering that I renounce to live for a death with dignity.

VI. The first country to approve euthanasia in the world was in 
Holland, and in Latin America it is Colombia, they are the same countries that have accepted euthanasia for minors.

\section{Acknowledgments}

None

\section{Conflicts of interest}

The author declares that there is no conflicts of interest.

\section{References}

1. Carlos Gaviria Diaz. Judgment C-239, it demands for unconstitutionality. Constitutional Court. Colombia. 1997.

2. Antonio Jose Lizarazo Ocampo. Judgment T-721, action of guardianship Constitutional Court. Colombia. 2017.

3. Farfan Molina F. Euthanasia fundamental rights and penal Law. Colombia Bogota: New Juridical Publishing house. 2008.

4. Luis Ernesto Vargas Silva. Judgment T-970, action of guardianship. Constitutional Court. Colombia. 2014.

5. Ortega Diaz. To Euthanasia. From crime to fundamental human right. Colombia, Bogota: Publishing house Ibañez. 2015.
6. Resolution 1216 , by means of which one gives fulfillment to the fourth order of the Judgment T-970 of 2014 of the honorable Constitutional Court. Department of Health and the Social Protection. DO: 49.489. 2015.

7. Achilles Arrieta Gómez. Judgment T-322 action of guardianship. Constitutional Court. Colombia. 2017.

8. Decree 100 by means of which the Penal Code is sent. President of Justice. DO: 35.461. 1980.

9. Alberto Rojas Ríos. Judgment C-233 it demands for unconstitutionality. Constitutional Court. Colombia. 2014.

10. War, Yolanda, Goatee, Alejandra. Euthanasia in Colombia law office. Colombia, Bogota: Publishing house Ibañez. 2016.

11. Iván Humberto Escrucería Mayolo. Judgment T-423 action of guardianship. Constitutional Court. Colombia. 2017.

12. Gloria Stella Ortiz Delgado. Judgment C-327 it demands for unconstitutionality. Constitutional Court. Colombia. 2016.

13. Resolution 825 By means of which the procedure is regulated to make effective the right to die with dignity of the Children, Girls and Teenagers. Department of Health and the Social Protection. DO: 50.530. 2018.

14. Gloria Stella Ortiz Delgado. Judgment T-544 action of guardianship. Constitutional Court. Colombia. 2017. 